\title{
PCR ribotyping of clinically important Clostridium difficile strains from Hungary
}

\author{
EDIT URBÁN, JON S. BRAZIER*, JÓZSEF SÓKI, ELISABETH NAGY and BRIAN I. DUERDEN* \\ Institute of Clinical Microbiology, Faculty of Medicine, University of Szeged, 6725 Szeged, Hungary and \\ * PHLS Anaerobe Reference Unit, Department of Medical Microbiology and Public Health Laboratory, \\ University of Wales College of Medicine, Cardiff CF14 4XN
}

\begin{abstract}
Isolates of Clostridium difficile from different hospital wards at the University Hospital of Szeged in Hungary were typed by PCR amplification of rRNA intergenic spacer regions (PCR ribotyping). A total of 15 different ribotypes was detected among the 65 isolates tested. The predominant type, PCR ribotype 087, accounted for $39 \%$ of all isolates, in contrast with an international typing study where ribotype 001 was the most common. Two non-toxigenic $C$. difficile strains were found to exhibit the same pattern, which was distinct from those of all the ribotypes described previously, suggesting that this is a new type.
\end{abstract}

\section{Introduction}

Clostridium difficile, an obligately anaerobic grampositive spore-forming rod, is a common nosocomial enteric pathogen world-wide. It causes pseudomembranous colitis (PMC), antibiotic-associated diarrhoea (AAD) or colitis (AAC) $[1,2]$. The spectrum of these diseases ranges from uncomplicated mild diarrhoea to lethal toxic megacolon or colon perforation, or both $[3,4]$. Since the 1980 s, several studies have documented the nosocomial acquisition of $C$. difficile. Some hospital wards have a high rate of colonisation by these micro-organisms. Despite major efforts to control the spread of $C$. difficile-associated diarrhoea (CDAD) in health-care facilities, this pathogen remains a problem world-wide that continues to be responsible for both endemic and epidemic nosocomial diarrhoea [5-8]. $C$. difficile infections have become a considerable problem in most European countries, including Hungary [5-8]. The laboratory isolation and identification of nosocomial $C$. difficile strains have necessitated the development of typing methods to provide a better follow-up of the epidemiology of the disease and to afford a better insight into the pathogenicity of various strains. Typing methods have been developed on the basis of various phenotypic and genotyping markers. The phenotypic markers include toxin production, antimicrobial resistance patterns, bacteriocin and bacterio-

Received 20 Feb. 2001; revised version accepted 11 June 2001.

Corresponding author: Professor E. Nagy (e-mail: nagye@ mlab.szote.u-szeged.hu). phage susceptibility patterns and whole-cell protein electrophoretic patterns, including ${ }^{35} \mathrm{~S}$ methioninelabelled protein patterns [9-11]. Immunological markers have been described for serotyping based on the Western blot method and serogrouping by slide agglutination [12-14]. Although serotyping and phage typing are simple and useful methods, only a few laboratories can perform them because these methods require the maintenance of stocks of sera and specific phages. It has been shown that phage typing may be difficult to use because of the frequent lysogeny of $C$. difficile strains [10]. Isolates have also been fingerprinted by pyrolysis mass spectrometry (PMS), according to the profiles of the volatile products $[15,16]$. Although this is a rapid technique, the disadvantage of PMS is that results for isolates that have been processed in different batches cannot be compared directly. Epidemiological markers based on genotypic characteristics are generally more discriminating and specific than phenotypic markers. Plasmid profiles, DNA restriction endonuclease and ribosomal rRNA restriction patterns have been used in the fingerprinting of C. difficile [17-19]. O'Neill and colleagues [20] developed a modification of the PCR ribotyping method based on polymorphisms in the $16 \mathrm{~S}-32 \mathrm{~S}$ rRNA intergenic spacer region for the routine typing of $C$. difficile. This part of the genome has been shown to be very heterogeneous, in contrast to the rRNA genes themselves, which are highly conserved. $C$. difficile was shown to possess up to 10 or more copies of the rRNA genes in its genome, which varied not only between strains, but also between different copies on the same genome. This modified PCR ribotyping 
method offers several advantages over other methods and appears to hold good promise for the typing of wild isolates of $C$. difficile.

The aim of this study was to determine the most common ribotypes of $C$. difficile in the 1200-bed University Hospital of Szeged, Hungary, and compare them with those found in the PHLS Anaerobe Reference Unit in Cardiff, UK.

\section{Materials and methods}

\section{Bacterial isolates}

Of the 65 C. difficile isolates investigated in this study, 57 were isolated from diarrhoeal faecal samples and 8 from other clinical materials (Table 1). Three reference strains were included as controls: $C$. difficile NCTC 11382 (toxin A-positive, toxin B-positive), C. difficile CCUG 20309 (toxin A-negative, toxin B-positive) and C. difficile NCTC 11206 (toxin A-negative, toxin Bnegative). Isolation and identification of $C$. difficile were performed according to standard methods.

\section{Toxin detection}

Single colonies were subcultured on pre-reduced Columbia Agar Base (Oxoid) supplemented with cattle blood $5 \%$, vitamin $\mathrm{K}_{1}$ and haemin and incubated at $37^{\circ} \mathrm{C}$ under anaerobic conditions (anaerobic chamber; Bactron Sheldon Man, OR, USA) for $24 \mathrm{~h}$ for toxin A detection. The production of toxin A by isolates of $C$. difficile was determined by an ELISA method (ToxA TEST Immunoassay; TechLab, BioConnections, Leeds, W. Yorkshire). Toxin B was detected by cytotoxicity assay on Vero cells. The cytopathic effects of filtered chopped-meat glucose broth culture supernates (diluted 1 in $10-1$ in $10^{4}$ ) on Vero cells were used to detect toxin B. All toxin B-positive samples were neutralised with specific $C$. difficile goat antitoxin.

\section{PCR ribotyping method}

Isolates were cultured anaerobically overnight on Fastidious Anaerobe Agar (FAA; LabM, Bury) supplemented with horse blood $6 \%$ in anaerobic conditions. Approximately 10 colonies were picked and crude template nucleic acid was prepared by resuspending the cells in Chelex-100 (BioRad, Hemel Hempstead) 5\% $\mathrm{w} / \mathrm{v}$ and boiling for $12 \mathrm{~min}$. After the removal of cellular debris by centrifugation ( $15000 \mathrm{~g}$ for $10 \mathrm{~min})$, $10 \mu \mathrm{l}$ of supernate were added to $90 \mu \mathrm{l}$ of PCR mixture containing $50 \mathrm{pmol}$ of each primer, Taq polymerase (Pharmacia) $2 \mathrm{U}$ and $2.25 \mathrm{mM} \mathrm{MgCl}_{2}$. Reaction mixtures were subjected to 35 cycles of denaturation at $94^{\circ} \mathrm{C}$ for $1 \mathrm{~min}$, annealing at $55^{\circ} \mathrm{C}$ for $1 \mathrm{~min}$ and extension at $72^{\circ} \mathrm{C}$ for $2 \mathrm{~min}$. Amplification products were concentrated to a final volume of $25 \mu \mathrm{l}$ by heating at $75^{\circ} \mathrm{C}$ for $90 \mathrm{~min}$ before electrophoresis at $100 \mathrm{~mA}$ and $200 \mathrm{~V}$ in Metaphor agarose (FMC Bioproducts,

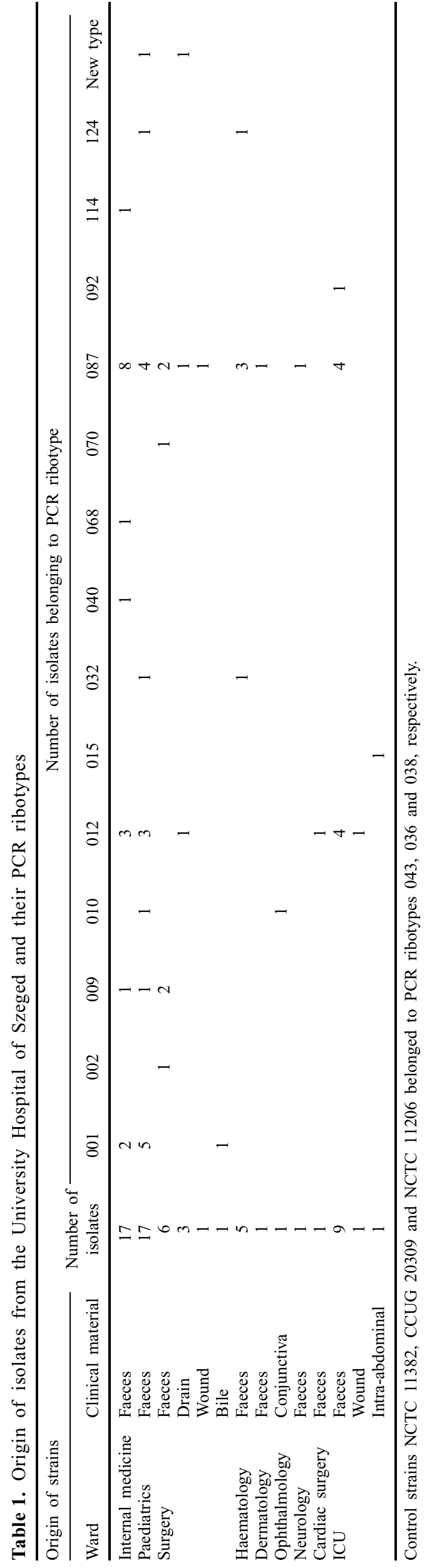


Rockland, ME, USA) $3 \%$ for $4.5 \mathrm{~h}$ at $8^{\circ} \mathrm{C}$. Products were visualised by staining the gel for $20 \mathrm{~min}$ in ethidium bromide $0.5 \mu \mathrm{g} / \mathrm{ml}$. To enable normalisation of all gel patterns, a molecular size standard (100 bp; Advanced Biotechnologies, Epsom) was run at fivelane intervals [20].

PCR ribotyping uses specific primers complementary to the $3^{\prime}$ end of the $16 \mathrm{~S}$ rRNA gene and the $5^{\prime}$ end of the 23S rRNA gene to amplify the variable-length intergenic spacer region. The oligonucleotide primers used were 5'-CTG GGG TGA AGT CGT AAC AAG G-3' (positions 1445-1466 of the 16S rRNA gene) and $5^{\prime}$ GCG CCC TTT GTA GCT TGA CC-3' (positions 201 of the 23S rRNA gene) [20].

Gel images were analysed with GelCompar image analysis software (version 4.0; Applied Maths, Kortrijk, Belgium). The criterion for the proposal of a new library type was the existence of clearly discernible, reproducible differences in PCR ribotype pattern from those of all other existing types.

\section{Results}

The sources and PCR ribotypes of the isolates are listed in Table 1. All the isolates originated from different patients in various wards at the University Hospital of Szeged. Most of them were hospitalised in the Internal Medicine, Paediatrics and Surgery Departments and Intensive Care Unit.

In-vitro toxin testing of the isolates revealed that there were both toxigenic and non-toxigenic isolates in the samples. During a period of 3 months, $57 \mathrm{C}$. difficile strains were isolated from 252 faecal samples; 44 of them $(77 \%)$ were toxin-producing, as detected by an immunoassay for the detection of $C$. difficile toxin A and cytotoxicity on Vero cells (toxin B). Six $(75 \%)$ of the eight clinical isolates from samples other than faeces collected during the same period were toxinproducing. Toxin A-negative, toxin B-positive strains were not isolated during this period.

The PCR ribotypes consisted of patterns comprising 312 bands, with the size of the bands varying from $c$. 250 to $600 \mathrm{bp}$ (Fig. 1). A total of 15 different ribotypes was detected among the 65 isolates tested (Table 2) $[12,21]$. The 50 toxigenic isolates $(77 \%)$ could be classified into seven visually distinct ribotypes, and the 15 non-toxigenic isolates into eight PCR ribotypes. Of the 50 toxigenic isolates tested, $46(92 \%)$ belonged to three PCR ribotypes (087, 012 and 001); type 087 was the most common ribotype, accounting for $50 \%$ (25 of $50)$ of the toxigenic isolates tested. The remaining four isolates $(8 \%)$ belonged to four other ribotypes. There was a wider distribution of ribotypes among the nontoxigenic isolates. A total of 15 toxin-negative isolates was investigated and ribotype 009 was isolated most frequently (4 of 15). Two non-toxigenic isolates belonging to ribotype 010 were isolated from conjunctiva and from the faeces of a newborn infant. This PCR ribotype is frequently isolated from the faeces of neonates and small children.

There was no significant correlation between the PCR ribotypes and the origin of the isolates investigated in this study as regards wards or patients' rooms. Some of the $C$. difficile isolates originating from different wards of the University Hospital of Szeged in Hungary belonged to the same ribotype as $C$. difficile isolates collected in the UK by the Anaerobe Reference Unit in Cardiff. All but two of the Hungarian isolates could be typed by this PCR ribotyping method, the exceptions were non-toxigenic isolates (one from faeces and one

\section{$\begin{array}{lllllllllllllllll}\mathrm{L} & 1 & 2 & 3 & 4 & 5 & 6 & \mathrm{~L} & 7 & 8 & 9 & 10 & 11 & 12 & 13 & \mathrm{~L}\end{array}$}

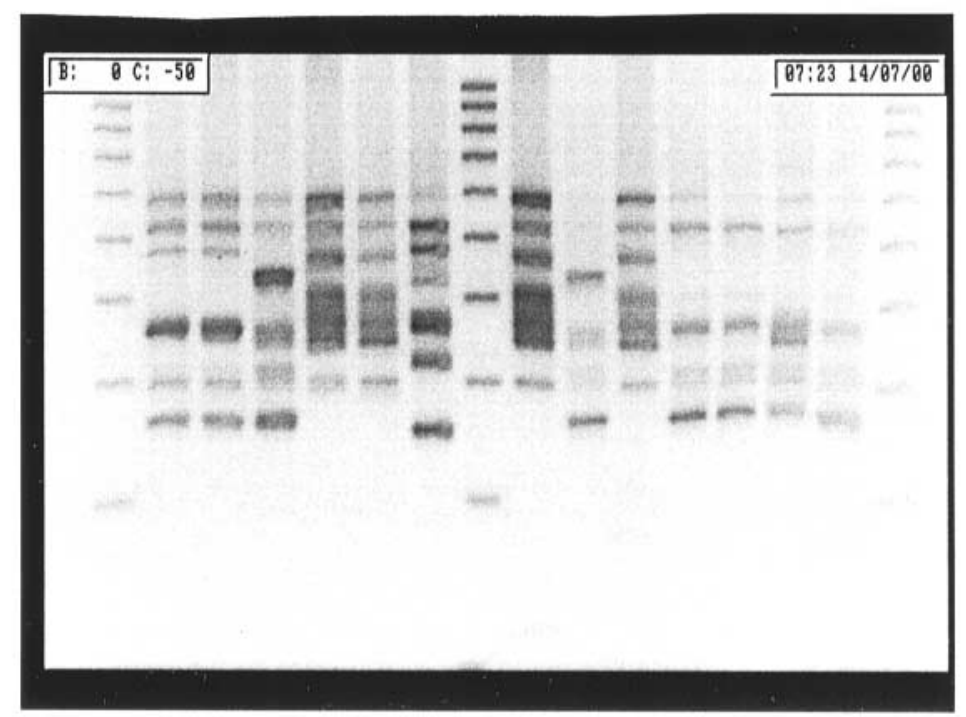

Fig. 1. PCR ribotype profiles found most frequently in Hungarian isolates of $C$. difficile. Lane L, 100-bp ladder; 1, 2, ribotype 015 ; $\mathbf{3}, \mathbf{8}$, ribotype $087 ; \mathbf{4}, \mathbf{5}, \mathbf{7}, \mathbf{9}$, ribotype $012 ; \mathbf{6}$, ribotype $010 ; \mathbf{1 0}-\mathbf{1 3}$, ribotype 001 . 
Table 2. Distribution of PCR ribotypes among Hungarian $C$. difficile isolates

\begin{tabular}{|c|c|c|c|c|c|c|}
\hline \multirow{2}{*}{$\begin{array}{l}\text { PCR } \\
\text { ribotype }\end{array}$} & \multirow{2}{*}{$\begin{array}{l}\text { Reference } \\
\text { strain of the } \\
\text { ribotype* }\end{array}$} & \multirow{2}{*}{$\begin{array}{l}\text { Number } \\
(\%) \text { of } \\
\text { isolates }\end{array}$} & \multicolumn{2}{|c|}{$\begin{array}{l}\text { Production of } \\
\text { toxin }\end{array}$} & \multirow{2}{*}{$\begin{array}{l}\text { Serogroup }^{\dagger} \text { of } \\
\text { the reference } \\
\text { strain }\end{array}$} & \multirow[b]{2}{*}{ Toxino-type } \\
\hline & & & A & B & & \\
\hline 001 & R8366 & $8(12.3)$ & + & + & G & 0 \\
\hline 002 & $\mathrm{R} 8375$ & $1(1.5)$ & + & + & A2 & 0 \\
\hline 009 & R8269 & $4(6.3)$ & - & - & I & \\
\hline 010 & $\mathrm{R} 8270$ & $2(3.0)$ & - & - & D,E6 & \\
\hline 012 & R6187(S51) & $13(20.0)$ & + & + & $\mathrm{C}, \mathrm{A}, \mathrm{G}, \mathrm{K}$ & 0 \\
\hline 015 & R6685(S38) & $1(1.5)$ & + & + & G & 0 \\
\hline 032 & R6598 & $2(3.0)$ & - & - & UT & \\
\hline 040 & R100917 & $1(1.5)$ & - & - & UT & \\
\hline 068 & IS56 & $1(1.5)$ & - & - & UT & \\
\hline 070 & R9367 & $1(1.5)$ & + & + & $\mathrm{K}$ & I \\
\hline 087 & R11840 & $25(39.0)$ & + & + & G & 0 \\
\hline 092 & R10630 & $1(1.5)$ & + & + & UT & 0 \\
\hline 114 & R11212 & $1(1.5)$ & - & - & UT & \\
\hline 124 & R11919 & $2(3.0)$ & - & - & UT & \\
\hline New type & - & $2(3.0)$ & - & - & UT & \\
\hline
\end{tabular}

UT, untypable.

* Ribotype reference strains maintained in the Anaerobe Reference Unit in Cardiff, UK.

†Serogroup of the reference strains has been made to Delmée serotype [12].

Toxino-type of the reference strains was determined according to methods described previously [21].

from intra-abdominal drainage) (Table 2). These two isolates exhibited the same pattern, which was distinct from those of all the ribotypes described previously, suggesting that it is a new type. More investigations are required to classify it with the cluster correlation algorithm. The integrity of the library was tested with control C. difficile strains: C. difficile NCTC 11382, ribotype 043, was used as a toxigenic control strain. The non-toxigenic control strain was $C$. difficile NCTC 11206, which belonged to PCR ribotype 038, and the control toxin A-negative, toxin B-positive strain, CCUG 20309, belonged to ribotype 036 .

\section{Discussion}

PCR ribotyping has recently been proposed as an effective means of studying $C$. difficile epidemiologically [22-24]. The PHLS Anaerobe Reference Unit in Cardiff routinely uses this method [20]. It provides a typing service for referred isolates and, from $>2000$ strains examined, a library consisting of 116 distinct ribotypes has been constructed. In total, 54 different PCR ribotypes have been identified from hospital patients. Type 001 accounts for $68 \%$ of the total of all isolates from hospital patients in England and Wales [25]. Type strains within the library have also been analysed by other typing schemes and the PCR ribotyping method correlates with other typing schemes and allows subtyping of many of the types produced by other methods (Table 2) [25].

The International Typing Study (involving seven groups of experts from the UK, Belgium, Australia and the USA) in 1997 organised by Brazier [26], revealed that certain types were more common in each country, indicating the distribution of the same types in hospitals in these countries. There are only a few publications about the genetic relationship of pathogenic strains of $C$. difficile from various other parts of the world, especially with regard to the Eastern European countries. In Eastern Europe there has been only one study, in a Polish maternity hospital [27], where arbitrarily primed PCR and PCR ribotyping methods were used. All environmental isolates and 11 of 31 neonatal isolates were of a single type, type 1 . There have been attempts to establish some form of standardisation in the nomenclatures to decribe strains typed by the various study groups. At present these various types are uncoordinated and there is a lack of understanding as to how types relate to one another. The Polish ribotyping results have not been compared to the reference library of the Anaerobe Reference Unit in Cardiff and it could not be determined which PCR ribotype corresponds to their type 1 .

The present study compared the ribotypes of $65 C$. difficile isolates originating from patients in Szeged, Hungary, with the library of $C$. difficile ribotypes in the Anaerobe Reference Unit in the UK. Although this sample size is small, the isolates originating from Hungarian inpatients display a very different distribution of PCR ribotypes from that found by the Anaerobe Reference Unit in the UK. The most predominant ribotype in the Hungarian survey of 65 isolates was PCR ribotype 087 , a toxigenic type, which accounted for $39 \%$ of all isolates, in contrast with the results of the international typing study where its prevalence was much lower. This type was not common in England and Wales either; only eight isolates of this type were found among several hundred investigated isolates [25]. The present study found two non-toxin-producing isolates, of a previously unrecognised type. No significant correlation was found between the distribution of the PCR ribotypes and the origin of the isolates during this period. Although no data have been published on the 
prevalence of $C$. difficile infection or the epidemiology of $C$. difficile-associated diarrhoea in Hungary, the isolation of toxigenic $C$. difficile from hospitalised patients suggests that this pathogen may be responsible for certain cases of diarrhoea of undiagnosed origin and validates our efforts to establish its significance and conduct epidemiological studies in Hungary.

This work was supported by a grant from Hungarian Eötvös Scholarship and by grant no. T032385 from the Hungarian National Research Foundation (OTKA).

\section{References}

1. Bartlett JG. Antibiotic-associated diarrhea. Clin Infect Dis 1992; 15: 573-581.

2. Bartlett JG. Clostridium difficile: history of its role as an enteric pathogen and the current state of knowledge about the organism. Clin Infect Dis 1994; 18 Suppl 4: S265-S272.

3. George WL. Antimicrobial agent-associated diarrhoea in adult humans. In: Rolfe RD, Finegold SM (eds) Clostridium difficile - its role in intestinal disease. London, Academic Press. 1998: 31 .

4. Johnson S, Gerding DN. Clostridium difficile-associated diarrhea. Clin Infect Dis 1998; 26: 1027-1036.

5. McFarland LV, Mulligan ME, Kwok RYY, Stamm WE. Nosocomial acquisition of Clostridium difficile infection. $N$ Engl J Med 1989; 320: 204-210.

6. Johnson S, Clabots CR, Linn FV, Olson MM, Peterson LR, Gerding DN. Nosocomial Clostridium difficile colonisation and disease. Lancet 1990; 336: 97-100.

7. Barbut F, Corthier G, Charpak Y et al. Prevalence and pathogenicity of Clostridium difficile in hospitalized patients. A French multicenter study. Arch Intern Med 1996; 156: 1449-1454.

8. Burdon DW. Clostridium difficile: the epidemiology and prevention of hospital-acquired infection. Infection 1982; 10: 203-204

9. Sell TL, Schaberg DR, Fekety FR. Bacteriophage and bacteriocin typing scheme for Clostridium difficile. J Clin Microbiol 1983; 17: 1148-1152.

10. Nagy E, Földes J. Electron microscopic investigation of lysogeny of Clostridium difficile strains isolated from antibiotic-associated diarrhea cases and from healthy carriers. APMIS 1991; 99: 321-326.

11. Tabaqchali S, Holland D, O'Farrell S, Silman R. Typing scheme for Clostridium difficile: its application in clinical and epidemiological studies. Lancet 1984; 1: 935-938.

12. Delmée M, Homel M, Wauters G. Serogrouping of Clostridium difficile strains by slide agglutination. J Clin Microbiol 1985; 21: 323-327.

13. Nakamura S, Serikawa T, Mikawa M, Nakashio S, Yamakawa K, Nishida S. Agglutination, toxigenicity and sorbitol fermen- tation of Clostridium difficile. Microbiol Immunol 1981; 25: $863-870$.

14. Mahony DE, Clow J, Atkinson L, Vakharia N, Schlech WF. Development and application of a multiple typing system for Clostridium difficile. Appl Environ Microbiol 1991; 57: 1873-1879.

15. Magee JT, Brazier JS, Hosein IK et al. An investigation of a nosocomial outbreak of Clostridium difficile by pyrolysis mass spectrometry. J Med Microbiol 1993; 39: 345-351.

16. Cartmill TDI, Orr K, Freeman R, Sisson PR, Lightfoot NF. Nosocomial infection with Clostridium difficile investigated by pyrolysis mass spectrometry. J Med Microbiol 1992; 37: 352-356.

17. Clabots CR, Peterson LR, Gerding DN. Characterization of a nosocomial Clostridium difficile outbreak by using plasmid profile typing and clindamycin susceptibility testing. $J$ Infect Dis 1988; 158: 731-736.

18. Kuijper EJ, Oudbier JH, Stuifbergen WNHM, Jansz A, Zanen HC. Application of whole-cell DNA restriction endonuclease profiles to the epidemiology of Clostridium difficile-induced diarrhea. J Clin Microbiol 1987; 25: 751-753.

19. Samore MH, Bettin KM, DeGirolami PC, Clabots CR, Gerding DN, Karchmer AW. Wide diversity of Clostridium difficile types at a tertiary referral hospital. J Infect Dis 1994; 170: 615-621.

20. O’Neill GL, Ogunsola FT, Brazier JS, Duerden BI. Modification of a PCR ribotyping method for application as a routine typing scheme for Clostridium difficile. Anaerobe 1996; 2: 205-209.

21. Rupnik M, Avensani V, Janc M, von Eichel-Streiber C, Delmée M. A novel toxinotyping scheme and correlation of toxinotypes with serogroups of Clostridium difficile isolates. $J$ Clin Microbiol 1998; 36: 2240-2247.

22. Killgore GE, Kato H. Use of arbitrary primed PCR to type Clostridium difficile and comparison of results with those by immunoblot typing. J Clin Microbiol 1994; 32: 1591-1593.

23. Gürtler V. Typing of Clostridium difficile strains by PCRamplification of variable length $16 \mathrm{~S}-23 \mathrm{~S}$ rDNA spacer regions. J Gen Microbiol 1993; 139: 3089-3097.

24. Cartwright CP, Stock F, Beekmann SE, Williams EC, Gill VJ. PCR amplification of rRNA intergenic spacer regions as a method for epidemiologic typing of Clostridium difficile. $J$ Clin Microbiol 1995; 33: 184-187.

25. Stubbs SLJ, Brazier JS, O’Neill GL, Duerden BI. PCR targeted to the 16S-23S rRNA gene intergenic spacer region of Clostridium difficile and construction of a library consisting of 116 different PCR ribotypes. J Clin Microbiol 1999; 37: $461-463$.

26. Brazier JS, Borriello SP. Microbiology, epidemiology and diagnosis of Clostridium difficile infection. In: Aktories $\mathrm{K}$, Wilkins TD (eds) Clostridium difficile. Berlin, Springer-Verlag. 2000: 1-33.

27. Martirosian G, Kuipers S, Verburgh H, van Belkum A, MeiselMikolajczik F. PCR ribotyping and arbitrarily primed PCR for typing strains of Clostridium difficile from a Polish maternity hospital. J Clin Microbiol 1995; 33: 2016-2021. 